\title{
CLINICAL TRIAL OF CHLORHEXIDINE AND DIAMINODIPHENYLSULPHONE IN SUPERFICIAL OCULAR INFECTIONS*
}

\author{
BY \\ P. A. GRAHAM \\ Department of Ophthalmology, University of Manchester
}

IN recent years a new antibacterial agent, chlorhexidine ("Hibitane") has. become available (Davies, Francis, Martin, Rose, and Swain, 1954; Murray and Calman, 1955). This compound has a wide range of bacteriostatic activity against both Gram-positive and Gram-negative organisms and is of low toxicity. The development of bacterial resistance to chlorhexidine has not been demonstrated. It is now used extensively for general antisepsis, but until recently its application in the conjunctival sac has been limited by the irritant nature of the diacetate salt commonly employed. Recently a less irritant but still soluble salt, chlorhexidine gluconate, has become available. This may be used in strengths of up to 0.2 per cent. as against 0.05 per cent. for the diacetate compound.

Diaminodiphenylsulphone (D.D.S., "Dapsone") was first described by Fromm and Wittmann (1908) and attracted interest many years later when it was discovered to be active against streptococcal, pneumococcal, and staphylococcal infections (Buttle, Stephenson, Smith, Dewing, and Foster, 1937). In animals it is ten to one hundred times more powerful than the sulphonamides, but clinical trials of its systemic use in man showed toxic effects and the advent of the sulphonamides and later of the antibiotics. overshadowed it. More recently the drug has come into general use in the treatment of leprosy, and Pandit (1955) has reported favourably on its. topical use in eye infections.

23082 (3-(5 nitrofurfuralidine) oxindole), the second substance used in this. trial, is an experimental compound of high bacteriostatic activity against streptococci and staphylococci, having only slight bactericidal powers.

As chlorhexidine and D.D.S. are to some extent complementary in activity, a combination of the two was considered worthy of trial against a standard antibiotic preparation in current use. An ointment was chosen for the purpose, as chlorhexidine and D.D.S. form a precipitate in solution. The compound 23082 was included to compare its high bacteriostatic activity against the bactericidal effect of chlorhexidine with D.D.S.

\section{Material and Methods}

An initial trial was conducted to compare 0.2 per cent. chlorhexidine $/ 5$ per cent. D.D.S. ointment with neomycin ointment. This trial included all cases of superficial ocular infection attending the out-patients department: This preliminary

\footnotetext{
* Received for publication January 22, 1960.
} 
trial indicated that, while chlorhexidine/D.D.S. appeared to be effective in some cases of conjunctivitis, assessment was difficult because of the wide variation in the nature of the cases treated.

In view of this it was decided to try the preparation in cases of acute mucopurulent conjunctivitis only, and to compare its clinical effects with those of neomycin, 23082, and a placebo ointment. As any difference was likely to be small, and as typical muco-purulent conjunctivitis is not a very common condition in an ophthalmic clinic (most cases being treated by a general practitioner), an attempt was made to design a trial which would yield the maximum of information from the small number of cases available.

In each patient the duration of the symptoms and the presence or absence of previous treatment elsewhere was ascertained, and this information was used to allocate patients to groups of similar duration and previous treatment. The patients were grouped according to 3-day intervals up to 12 days, a fifth group comprising cases of over 12 days' duration. These five groups were then further sub-divided into treated and untreated patients, making ten groups in all. Within each of these ten groups successive patients were allocated to receive one of the four preparations by reference to a table of random permutations.

In this way it was hoped to minimize the effect of variations in the duration of the disease and of previous treatment. The treatment received was unknown to the patient or to the observer, who saw each patient at every attendance.

The ointment was applied 4-hourly during the trial period, and the number of days was noted from the start of treatment till complete relief of symptoms and disappearance of injection and discharge. No other treatment was applied during the period of the trial. If the conjunctivitis grew worse, the patient was removed from the trial and treated in the normal way.

\section{Results}

A total of 48 patients was treated. The Table shows the distribution of cases among the four preparations and the results obtained. The numbers treated with each preparation vary because only a group containing a multiple of four will have an even distribution. It proved impossible in practice to attain this ideal, but an examination of the distribution of cases suggests that the effect of this departure from the ideal trial is small.

TABLE

RESULTS IN 48 PATIENTS

\begin{tabular}{|c|c|c|c|c|c|c|c|}
\hline \multirow{2}{*}{ Drug } & \multirow{2}{*}{$\begin{array}{c}\text { Total } \\
\text { Cases } \\
\text { Starting } \\
\text { Trial }\end{array}$} & \multirow{2}{*}{$\begin{array}{c}\text { No. } \\
\text { Defaulted } \\
\text { During } \\
\text { Treatment }\end{array}$} & \multicolumn{2}{|c|}{ No. Removed } & \multicolumn{2}{|c|}{ Infection Resolved } & \multirow{2}{*}{$\begin{array}{c}\text { Mean } \\
\text { Time to } \\
\text { Resolve } \\
\text { (days) }\end{array}$} \\
\hline & & & $\begin{array}{c}\text { Derma- } \\
\text { titis }\end{array}$ & Worse & $>10$ days & $<10$ days & \\
\hline $\begin{array}{l}\text { D.D.S. } \\
\text { (Hibitane) }\end{array}$ & 11 & 1 & 0 & 1 & 2 & 7 & $6 \cdot 8$ \\
\hline Neomycin.. & 15 & 2 & 1 & 0 & 1 & 11 & $5 \cdot 8$ \\
\hline 23082 & 13 & 2 & 1 & 2 & 3 & 5 & $11 \cdot 6$ \\
\hline Placebo .. & 9 & 0 & 1 & 2 & 2 & 4 & $10 \cdot 8$ \\
\hline
\end{tabular}


The Table shows that there was little difference in the average duration of symptoms in patients treated with chlorhexidine/D.D.S. and neomycin, but a considerable difference between these groups and those receiving the placebo and 23082 ointments, a difference which is unlikely to be due to chance variation (comparing neomycin and chlorhexidine/D.D.S. with placebo, $t=2.120 .05>P>0.02$, and with " 23082 ", $t=2.080 .05>P>0.02$ ). The fact that one of the patients removed from the trial because of drug irritation was receiving the placebo ointment, raises the possibility that this complication was due to the ointment base in use.

\section{Discussion}

The results suggest that, where the conjunctivitis responded to the drug, the combination of 0.2 per cent. chlorhexidine/5 per cent. D.D.S. was probably as effective as neomycin; cases treated with either of these preparations resolved significantly more rapidly than those treated with 23082, which appeared to be no better than the placebo ointment.

The method of assessment used above does not, however, take into account those patients in whom the conjunctivitis became worse and who were accordingly removed from the trial. Most cases of conjunctivitis will probably resolve in a fairly short time without treatment, whereas an occasional case will not do so but persists or takes a very long time to resolve. If this latter type be treated with a preparation active against the causative organism, resolution should, however, be rapid. This hypothesis may be used in an alternative analysis of these results by expressing the number of cases deteriorating or taking over 10 days to resolve as a proportion of the total number treated with each ointment. This shows that 8 per cent. of neomycin cases, 30 per cent. of chlorhexidine/D.D.S., and 50 per cent. of both dummy and 23082 cases were either removed on account of deterioration or took a long time to resolve. This approach suggests that chlorhexidine/ D.D.S. may be less effective than neomycin, in that some cases fail to respond. It must be pointed out, however, that the apparently large differences in the proportions of unsuccessful cases are not in fact significant, and that the apparent advantage of neomycin might have occurred by chance. A larger trial might solve this question but was not considered worth undertaking.

From the evidence available it may be concluded that the combination of chlorhexidine/D.D.S. is active in many cases of conjunctivitis, and it remains to consider whether it has any advantage over the preparations of antibiotics in current use. Such advantage as it has lies in the probable low incidence of development of bacterial resistance and in the combination of a wide spectrum of activity with a high stability. On the debit side it must be noted that chlorhexidine and D.D.S. precipitate in solution and must be used either as an ointment or as a suspension, and it is possible that some 
cases do not respond to the combination at all. Its advantages are probably outweighed by its disadvantages, and it would seem that there is little point in adding this combination to the growing number of preparations in routine use for the treatment of superficial ocular infections. It might, however, be of use where special circumstances demand a widespectrum preparation having high stability under adverse storage conditions.

\section{Summary}

A clinical trial of chlorhexidine/D.D.S., 23082, and neomycin ointment in acute muco-purulent conjunctivitis is described. Chlorhexidine/D.D.S. was approximately as effective as neomycin in most cases, but some patients failed to respond. 23082 appeared to have little if any clinical activity.

I should like to thank Mr. O. M. Duthie and Dr. A. Stanworth for allowing me to treat these cases and for their comments. The materials used in the trial, which are not available commercially in this form, were provided by Imperial Chemical Industries, Ltd., whom I should like to thank for their co-operation.

\section{REFERENCES}

Buttle, G. A. H., Stephenson, D., Smith, S., Dewing, T., and Foster, G. E. (1937). Lancet, 1, 1331 .

Davies, G. E., Francis, J., Martin, A. R., Rose, F. L., and Swain, G. (1954). Brit. J. Pharmacol., 9, 192.

Fromm, E., and WitTMANN, J. (1908). Ber. dtsch. chem. Ges., 41, 2264.

MurRaY, J., and CalmaN, R. M. (1955). Brit. med. J., 1, 81.

PANDIT, Y. K. C. (1955). Indian Pract., 8, 971. 